\title{
Evaluating the Quality of Corporations' Commitment to their Economic Responsibilities: A Theoretical Study to Enrich the Thought of CSR
}

\author{
Submitted 20/12/21, 1st revision 14/01/22, 2nd revision 18/02/22, accepted 08/03/22
}

\author{
Younis A. Battal Saleh ${ }^{1}$
}

\begin{abstract}
:
Purpose: This study aimed to identify and describe the economic responsibilities of the departments included in the FOS of the corporation as the economic entities that contribute to achieving profit and through which the quality of the corporation's commitment to its economic responsibility can be judged.

Design/Methodology/Approach: To determine and describe the economic responsibilities of the departments that make up the organizational structure in any corporation, the concepts of effectiveness and efficiency in accomplishing the functions assigned to those departments were selected as an approach to define those responsibilities, with the need to define criteria for evaluating the quality of effectiveness and efficiency.

Findings: Through the concepts of effectiveness and efficiency in completing functions, this study was able to determine and describe the economic responsibilities for the senior management, the purchasing department, the production department and the marketing department that were chosen to be the subject of this study because they are actually the departments that have the most impact on the profit figure.

Originality/Value: The idea of this study, which depends on the concepts of effectiveness and efficiency in performing the functions, can be adopted in defining and describing the economic responsibilities of the departments included in the FOS of any for-profit corporation. This study is an enrichment of the thought of CSR, and it will be considered as the starting point for many studies and research in this field.
\end{abstract}

Keywords: Corporate Social Responsibility, Corporate Economic Responsibility, performance evaluation, effectiveness and efficiency, functional organizational structure.

JEL Classification: M14, H21, L22.

Paper type: Research article.

Abbreviations: Corporate Social Responsibility (CSR), Corporate Economic Responsibility (CER), Functional Organizational Structure (FOS).

\footnotetext{
${ }^{1}$ Mr. Lecturer And Researcher In Training Department In HRM Of General Electricity Company "GECOL" In Benghazi-Libya, battalsaleh@yahoo.com;
} 


\section{Introduction}

As stated in the thought of CSR, the CER is the maximization of profit. Based on this definition, does simply making a profit mean that the corporation is committed to its economic responsibility? Many corporations make profits. Does this mean that they are committed to their economic responsibility? The answer may be yes or no, but the logical answer is "no". Has the thought of CSR provided criteria by which to measure the quality of the corporation's commitment to its economic responsibility? The answer is definitely no. So, how can CER be evaluated? How can the quality of the corporation's commitment be judged? To get out of this predicament, the researcher believes that it is necessary to focus on evaluating the economic performance of the departments that make up the FOS of the corporation as they are the economic entities that contribute to making profit.

Evaluating the economic responsibilities of the departments is the only optimal way to judge the extent of the corporation's commitment or non-commitment to its economic responsibility. The meaning of profit maximization is not clear. What are the profit figures that can reflect the quality of the corporation's commitment to its economic responsibility? There is no accurate description of the meaning of the word "maximization". There are no limits to the profit numbers. This confusion allows the search of other methods to judge the quality of the corporation's commitment to its economic responsibility.

Those are the alternative methods by which the quality level of economic performance can be evaluated. The rise in the profit figure to a certain extent is not sufficient evidence of the corporation's commitment to its economic responsibility. Perhaps this limit "extent" is much less than the limit that could have been achieved if the economic performance had been going in the right direction. The economic performance of the corporation as a whole, which is reflected in the profit figure, all the departments included in the FOS of the corporation contribute to achieving it. Any failure "poor performance" in any department will affect the performance of the corporation as a whole. The low level of economic performance in any department means that the corporation is not committed to its economic responsibility as it should. For this reason, the profit figure appearing in the financial statements cannot be relied upon to measure the quality level of the corporation's commitment to its economic responsibility.

\section{Justifications for Defining and Describing the Economic Responsibilities of the Departments Included in the Corporation's FOS "A Logical Argument"}

According to the researcher's opinion, there are many logical justifications that support the idea of abandoning the profit number as a sole indicator to judge the extent of the corporation's commitment to its economic responsibility or the quality of the corporation's commitment to its economic responsibility. The logical vision proposed by the researcher in this study is the need to find an accurate description of the economic responsibilities of the departments included in the FOS of the 
corporation as they are the entities that directly contribute to making the profit figure. By evaluating the departments' commitment to their economic responsibilities - "evaluating the extent of their commitment to the concepts of effectiveness and efficiency in performing the functions assigned to them," the quality of the corporation's commitment to its economic responsibility can be judged.

1) Any profit figure that appears in the financial statements, "whether big or small," cannot reflect the quality level of the corporation's commitment to its economic responsibility due to the absence of logical criteria by which to evaluate the level of that quality. The thought of CSR did not provide any criteria to evaluate the level of quality of corporations' commitment to their economic responsibility. The appearance of profit in the financial statements may indicate that there is a commitment. The level of commitment- whether it is weak, good or excellent, can only be determined by studying and evaluating the economic performance of the departments that contributed to making that profit. Judging the corporation's commitment to its economic responsibility or the quality of the corporation's commitment to its economic responsibility should not be based on the profit figure appearing in the financial statements, but rather through evaluating the economic performance of the departments that contributed to achieving that figure.

The profit figure appearing in the financial statements is a summary of the positive and negative economic performance of the departments included in the corporation's FOS. It is a reflection of the economic performance of those departments. It represents the contribution of those departments to achieving the corporation's main objective "maximizing profit" - which is attributed to the corporation as a whole, by performing their functions effectively and efficiently. It is not possible to rely on this figure in evaluating the economic responsibility of corporation and measuring the level of quality of commitment unless the economic responsibilities of those departments are evaluated. For this reason there is a need to define and describe the economic responsibilities of the departments.

2) Since those who adhere to the requirements of CSR are the departments that make up the corporation's FOS - but the results of the evaluation are attributed to the corporation as a whole, this means that these departments have social responsibilities "economic, legal, ethical, philanthropic" that must be defined and described with extreme accuracy.

3) CER means maximizing profit by reducing costs and increasing revenues. These requirements "reducing costs and increasing revenues" are in fact one of the functions and responsibilities of the departments included in the corporation's FOS. In order to achieve profits, all corporations are interested in reducing costs to the lowest possible level "the avoidable costs." This burden or responsibility rests with all departments in the corporation. Reducing costs can be considered one of the criteria for evaluating the economic performance of these departments and one of 
their most important economic responsibilities. Accordingly, it will be necessary to define and describe the economic responsibilities of these departments with regard to the need to monitor the costs of completing their functions, according to specific criteria that are compatible with the nature of their functions.

4) The positive and negative economic performance of the departments affects the performance of the corporation as a whole, as well as the interests of stakeholders and other parties in society. As a result, it will be necessary to define the responsibilities of those departments, especially the economic responsibilities. For example, purchasing raw materials in large quantities "that are not economically justified" by the Purchasing and Warehouse Department may contribute to an increase in the prices of these materials in the local market and then cause economic damage to other parties that need those materials "competing corporations."

As well, buying in quantities that are not economically justified may cause economic damage to the corporation as a whole as a result of high storage costs and damage to raw materials stored for long periods "spoilage of raw material stocks." In a more precise sense, the production of large quantities that are not economically justified by the production department may cause economic damage to the corporation itself, and to the stakeholders and other parties in society. These violations can be considered a clear obstacle to the issue of economic sustainability that contemporary societies seek to achieve.

5) The departments included in the FOS of the corporation are economic entities within the large entity "the corporation," that possess the economic resources "financial and human," powers and authorities that must be managed effectively and efficiently in order to contribute to achieving the goal of the corporation as a whole "profit maximization." They are centers that contribute to maximizing the corporation's profit. They are responsible entities and can be held accountable for their performance. Proceeding from the principle of accountability as one of the principles of CSR, these departments are accountability centers as entities that possess the economic resources, authorities and powers necessary to perform their functions. As long as there is accountability, there must be responsibility. Accordingly, the economic responsibilities of these departments must be defined and described.

\section{Evaluating the CSR and Judging the Corporation's Performance}

When evaluating CSR, the result of the evaluation- whether it is a failure or a distinction, is attributed to the corporation as a whole, while the evaluation through which the report is issued is a result of evaluating the social performance of all the departments included in the FOS of that corporation. This means that all the departments included in the corporation's FOS have social responsibilities. Making a judgment about the extent to which the corporation as a whole is committed to its social responsibility will depend on the extent to which its departments are committed to their social responsibility. Also, the quality of the company's 
commitment to its social responsibility will depend on the quality of its departments' commitment to their social responsibility. Based on the fact that each department included in the FOS of any corporation has a special task that differs from the tasks of other departments, it will be necessary to determine and describe the social responsibilities of the departments.

With regard to determining and describing the social responsibilities of the departments included in the FOS of the corporation, it can be said that, the philanthropic, ethical and legal responsibilities of the departments are clear and there is no problem with them. The meanings of these responsibilities for departments are not different from their meanings for the corporation as a whole. As for the economic responsibility, it is not specified for the departments. The economic responsibility of the corporation as a whole means profit maximization. As for the departments, this responsibility needs to be defined and described accurately according to logical criteria that must correspond to the nature of the various tasks of those departments. The thought of CSR did not specify the nature of the economic responsibility entrusted to the departments included in the corporation's FOS. This problem is considered one of the failures of the thought of CSR, which this study tries to solve.

The results of the evaluation of the social responsibility of any corporation are a summary of the commitment and non-commitment of its senior management and executive departments to their own social responsibilities. The commitment or noncommitment of the corporation to its social responsibility is in fact the commitment or non-commitment of one or some or all of the departments included in the FOS of that corporation to its $\backslash$ their social responsibilities entrusted to it $\backslash$ them under its statute. In a more precise sense, the evaluation of CSR is in fact an evaluation that includes all the departments listed in the corporation's FOS, but the final evaluation result is attributed to the corporation as a whole. For example, assuming that, the human resources department in the General Electricity Company of Libya is not committed to its social responsibility towards workers in the field of training on safety and security precautions. This failure "non-compliance" will be attributed to the corporation as a whole, and not to the human resources department.

\section{Social Responsibilities of the Corporation's Departments}

The content of the social responsibilities (economic, legal, ethical and philanthropic) of the departments included in the FOS of the corporation is the same as the content of the CSR except for the economic responsibility whose meaning is different for the departments. The economic responsibility of the departments means the effective and efficient completion of functions in order to contribute to maximizing the profit of the corporation. The economic responsibility of the departments "be effective and efficient when completing work tasks"; The legal responsibility of the departments "obey the laws and Regulations"; The ethical responsibility of the departments "be ethical when completing work tasks"; The philanthropic responsibility of the 
departments "be committed to the corporation's philanthropic policies and strategies".

\subsection{Description of the Study Problem}

The researcher describes the theory of CSR as a plane that took off from the airport runway and did not settle in the air yet. The CSR is a modern thought that is still under development and improvement. Academics specializing in this field are aware that there are many challenges and issues that hinder the process of implementing this thought- on the ground, to the fullest. The challenges and issues associated with the idea of CSR are many, and one of those issues is what this study raises.

Profit figures that appear in the financial statements are not sufficient evidence of corporations' commitment to their economic responsibility due to the lack of criteria for evaluating and measuring the quality of commitment. In order to overcome this problem, the researcher suggests adopting the idea of evaluating the economic responsibilities of the departments included in the corporation's FOS as entities that contribute to making profit "entities through which profit is achieved." By reviewing the content of the thought of CSR, there is no accurate definition of economic responsibility except that definition that describes the economic responsibility of the corporation as a whole. Therefore, the study problem can be identified as follows:

The thought of CSR defines the economic responsibility of the corporation as a whole, which means "maximizing profit", and does not determine and describe the economic responsibilities of the departments included in the corporation's FOS.

To get out of this predicament, this study came as the first initiative to address this problem.

\subsection{The Purpose of the Study}

Evaluating the social performance or social responsibility of the departments included in the FOS of any corporation in a separate and independent manner will contribute to determining which departments whose social performance contributed to the enhancement or deterioration of the social performance of that corporation as a whole. To this end, the social responsibilities of the departments within any corporation must be defined and described in a manner consistent with the functions of those departments. In order to show how to achieve this goal, this initiative came as a literary contribution to enrich the thought of CSR, and to open the way for thinkers and writers in this field.

This initiative is as a proactive step, dedicated to identifying and describing the economic responsibility of the departments, relying on the concepts of effectiveness and efficiency as logical concepts that are closely and directly related to the economic performance of any corporation. In this study, the top management, 
purchasing department, production department and marketing department - of any industrial enterprise, are selected to determine their economic responsibilities- as the departments whose performance strongly and directly affects the profit figure. Accordingly, this study aims to determine and describe the economic responsibilities of the most important departments included in the industrial corporation's FOS by relying on the concepts of effectiveness and efficiency.

\subsection{The Importance of Studying}

This study indicated a very important issue, which is the impossibility of evaluating the quality of companies' commitment to their economic responsibilities based on the profit figures achieved. As the profit figure appearing in the financial statements is considered insufficient to achieve this end due to the lack of criteria to judge the quality of that figure. As an initiative to solve this problem, this study suggested the necessity of evaluating the economic responsibilities of the departments that contribute to making profit by evaluating the extent of their commitment to perform the tasks assigned to them effectively and efficiently. Accordingly, this study can be considered as a scientific enrichment of the thought of CSR, especially in the field of evaluating economic responsibility as one of the types of corporate social responsibilities.

\subsection{Research Methodology}

The method is "an innovative approach to determining the economic responsibilities of the departments included in the corporation's FOS". This study adopted the concepts of effectiveness and efficiency in performing functions as an approach to identify and describe the economic responsibilities of the departments included in the FOS of any for-profit corporation. Since the functions of the departments in any corporation are different, the criteria for measuring and evaluating the quality of effectiveness and efficiency in the performance of functions will differ from one function to another "from one department to another." Each job has logical criteria to measure the quality of effectiveness and efficiency in performing that job, through which the effectiveness and efficiency of the department in performing its job duties can be evaluated. Evaluating the effectiveness of the departments in performing the functions assigned to them, it can be measured by comparing the actual performance with the planned $\backslash$ required performance. As for efficiency, it can be measured by time, specifications, costs, quality, development, improvement and innovation, seizing opportunities, etc.

\section{Findings and Discussion}

As is known, to evaluate the performance of anything "a machine, a person, a department, a company, a government, etc." there must be logical criteria by which the actual performance can be compared to the described performance of this thing. Through the result of the comparison can be judged on the quality of the actual 
performance. Whenever the performance is similar to what is specified in those standards or close to it, the performance is excellent and of high quality.

However, it is not always possible to rely on the results of the comparison in judging the quality of performance due to the distortions associated with the criteria used in the measurement and comparison process, as is the case when evaluating the economic performance of corporations. In the field of evaluating the corporate economic performance - "the corporate economic responsibility as one of the types of corporate social responsibilities - according to the Carroll pyramid," the profit figure is usually used as a criterion for evaluating that performance.

Unfortunately, although this standard is adopted by most corporations, it is inaccurate and not suitable for judging the quality of corporations' commitment to their economic responsibilities for the following reasons:

$>$ the participation of more than one department in achieving the profit figure planned by the corporation's management. Adopting the profit figure as a criterion for evaluating the company's performance may hide failures of some departments and distinct successes of other departments "distinct successes may hide severe failures";

$>$ the environments in which corporations operate are often volatile, unstable and uncontrollable environments that directly affect the performance of those corporations, either positively or negatively. Changes in the conditions of the external environment surrounding the corporations "political, economic, social and cultural conditions" contributes to the enhancement or deterioration of the actual performance of those corporations. Therefore, comparing the actual performance with the planned performance is useless;

$>$ the failure of the corporation's management to estimate the planned performance may make the bad performance in the eyes of that management as an ideal performance, and vice versa.

It is not possible to reach the degree of perfection regarding the accuracy of estimating economic performance. This means that the basis for comparison "planned performance" is inaccurate and cannot be relied upon in measuring the quality of the corporation's commitment to its economic responsibility.

In practical life, it is very rare for the actual economic performance of companies to match the planned performance. Usually there are positive or negative deviations. These deviations are due to one or both of the following reasons: management's failure to make budget estimates or executive departments' failure to implement the plan. These deviations, unless they are due to circumstances beyond the control of management, will distort the standard of comparing actual performance with the planned performance to measure the quality of the corporation's commitment to its economic responsibility. 
In addition to the above, the researcher presents another logical argument to reinforce the idea of rejecting the adoption of planned economic performance as a criterion for measuring the quality of companies' commitment to their economic responsibility. This argument is: Corporate economic responsibility means maximizing profit, which will only be achieved through optimal use of economic resources. To maximize profit, costs must be reduced to the lowest level and revenue must be raised to the highest level.

In the industrial firms operating in the competitive market with market share system in place, the production capacity of the factories will not be operating at full capacity. In this regard, failure to operate the factory at its full capacity may indicate the inability of the administration to maximize profit by finding new marketing channels. This means that there is idle and untapped production capacity that will distort the meaning of the quality of commitment to economic responsibility, whose content emphasizes the optimal use of economic resources. Also, that idle production capacity will distort the rate of return on investment and the asset turnover ratio.

In countries that adopt the capitalist and socialist system together such as Libya, public sector companies that are partly funded by the state's public treasury - such as GECOL in Libya, there is an overestimate the planned economic performance in order to get the largest amount of money from the state's public treasury. This exaggeration will contribute to distorting the standard of comparing actual performance with planned performance to measure the quality of the corporation's commitment to its economic responsibility. As well as, these companies are established for the purpose of supporting citizens. The prices of their services and goods are designed to support citizens and not to maximize profit. This approach contributes to distorting the meaning of CER "profit maximization."

Therefore, it is necessary to search for another meaning of economic responsibility and alternative ways to measure the quality of these companies' commitment to their economic responsibility in line with their objectives.

Based on the above considerations, the conformity of the actual performance with the planned performance cannot be considered a measure of the quality of commitment. To evaluate the quality of a corporation's commitment to its economic responsibility, it would be better to focus on how the actual economic performance is achieved rather than comparing it with the planned performance.

Evaluating the quality of corporations' commitment to their economic responsibilities by relying on profit figures appearing in the financial statements is a wrong procedure. Profit figures, no matter how big or small, do not reflect the quality of the commitment. Profit figures only indicate that there is a commitment by the corporation to its economic responsibility, but it cannot reflect the level of quality of that commitment. The quality of commitment to economic responsibility 
does not mean that the actual economic performance of the corporation must match the planned economic performance of that corporation, or in other words, it does not mean that the actual profit number must match the planned profit figure. This problem is one of the issues that may be unknown of many who are interested in the thought of CSR (Saleh, 2020).

Corporate economic responsibility - as it is known, means profit maximization. The word maximization is an undefined word. In other words, what is the amount of profit by which one can judge the quality of the corporation's commitment to its economic responsibility? Therefore, to evaluate the quality of the corporation's commitment to its economic responsibility, the researcher suggests the need to focus on how the profit figure is made and not on the profit figure in itself.

\subsection{Economic Responsibility}

The researcher divides the corporate economic responsibility according to their impact into:

1) Corporate Economic Responsibility at the Level of the Corporation's Economy:

Economic Responsibilities: "Be profitable, maximize revenues and minimize expenses." Economic responsibilities relate to business's provision of merchandise and services in community. Earnings result from this activity and are necessary for any other responsibilities to be carried out. It is assumed that corporations will be as profitable as possible, maintain a powerful competitive position and maintain a high level of operating efficiency. It is well known that many developing countries suffer from a shortage of foreign direct investment, as well as from high unemployment level and widespread poverty. It is no surprise, therefore, that the economic contribution of companies in developing countries is highly prized, by governments and communities, alike (Carroll, 1991; Al Am, 2020).

2) Corporate Economic Responsibility at the Level of the Country's Economy as a Whole:

This concept should be strengthened and adopted in developing and poor countries, which particularly states the following: "when seeking to maximize profits, corporations must not harm the national economy of the state, even if the laws do not criminalize this." Corporations should contribute to strengthening the national economy of the state, "strengthening the state's national wealth." Corporations are one of the main components of any country's economy, and they can influence it, either positively or negatively. We may applaud the profitable corporation "the company that made the highest profit," and at the same time we may regret the negative effects that this corporation has left at the level of the country's economy as a whole. For example, hiring foreign workers and ignoring national workers. This behavior "action" contributes to increasing unemployment rates in society and also contributes to the exit of hard currency outside the borders of the state. 
Another example, reducing sales prices in order to sell a larger quantity of products may contribute to pushing another competitor out of the market. Corporate economic responsibility can be viewed from two angles: maximizing the company's profit and strengthening the national economy of the state (Saleh, 2021).

\subsection{Accountability as One of the Principles of CSR}

According to ethics activist Geoff Hunt, accountability is the readiness or preparedness to give an explanation or justification to relevant others (stakeholders) for one's judgments, intentions, acts and omissions when appropriately called upon to do so. It is (also) a readiness to have one's actions judged by others and, where appropriate, accept responsibility for errors, misjudgments and negligence and recognition for competence, conscientiousness, excellence and wisdom. It is a preparedness to change in the light of improved understanding gained from others (Bivins, 2006). In fact, "accountability as a concept is closely related to responsibility. There can be no accountability- in its true sense, regarding any issue unless there is a specific and clear responsibility" (Al- Husseini, 2017).

In the business world, stakeholders are not entitled to accountability for performance until after the assignment of responsibilities, granting powers and allocating economic resources. The main goal of accountability is not to praise or punish, but to correct deviations. Accountability is a control process that aims to obtain explanations and justifications about the actions carried out, or decisions taken or measures followed that the other party (stakeholders) deems to contradict what is described and specified.

Based on the evaluation of those explanations and justifications, certain actions and reactions will be taken against non-compliant officials or departments. Corporate accountability can be defined as the ability of those affected by a corporation to hold corporations to account for their operations (Friends of the Earth, 2005). Corporate accountability means that the corporation is responsible for the results of its work and for any deviations that may occur from its goals and values to stakeholders such as shareholders, customers, employees, government agencies, etc. Accountability is very important and necessary to ensure that corporations adhere to their social responsibility towards all concerned parties and redirect that commitment in the right direction in case of deviation.

\subsection{Effectiveness and Efficiency}

Effectiveness is the power to produce the desired result. Efficiency is defined as the ability to do something or produce something without wasting materials, time, or energy ( Wilson et al., 2018). Effectiveness and efficiency are terms that have a great meaning in evaluating and measuring the performance of organizations. The continued presence of business organizations in the environment in which they operate depends on the extent to which their goals are effectively and efficiently 
achieved. Effectiveness and efficiency are not the same thing, each has a different meaning. In the business world, in light of the existence of the FOS in business organizations, each department has special tasks and functions to achieve the goals of the organization as a whole. Administrative effectiveness is the ability of the department to carry out its functions to achieve the desired results or planned goals for the organization as a whole.

Effectiveness means the extent to which the administration accomplishes its specific tasks entrusted to it to contribute to achieving the objectives of the organization. Effectiveness means the achievement of the desired goals, as well as the accomplishment of the assigned tasks. It can be measured by comparing the achieved result $\backslash$ performance with the desired result $\backslash$ performance. For departments included in the corporation's FOS, it can be measured by the percentage of completion of the specified tasks. Effectiveness is related to the ability to achieve the intended goals, not to how those goals are achieved.

While, efficiency refers to how goals are achieved or tasks are accomplished. In a more precise sense, it refers to the material and immaterial costs incurred in order to achieve the goals and accomplish the tasks. For departments included in the corporation's FOS, efficiency means accomplishing those specific tasks in the right way " with the least amount of wasted time, money, and effort or competency in performance." According to Nelly (1998), performance measurement is the process of quantifying the efficiency and effectiveness of past action. It is the gathering of information about the work effectiveness and productivity of individuals, groups, and larger Organizational units (Larsen and Callahan, 1990). It involves systematically collecting and strategically using information, on an ongoing basis, in an intra- and inter-organizational fashion, and for a variety of internal and external purposes (Dusenbury, 2000; Omosa, 2005).

\subsection{The Importance of the FOS in Evaluating the CSR}

FOS refers to the structure in which different departments are created on the basis of main functions accomplished in the organization. Organizational structure is a way or method by which organizational activities are divided, organized and coordinated (Ahmady et al., 2016). Functional organizations contain specialized units that report to a single authority, usually called top management.

Every corporation has goals that it strives to achieve. These goals can only be achieved through a set of various functions, which differ in nature from one job to another. This diversity of tasks and functions requires the corporation to create what is known as the FOS, which usually consists of several departments, each department has its own tasks and duties that it must undertake in order to contribute to achieving the goals of the corporation as a whole. In large institutions, in order for these departments to be able to perform their tasks to the fullest, they must be given the powers, authorities and economic resources necessary to accomplish those tasks, 
with the need to evaluate the results of the work of those departments to determine the extent of their impact on the performance of the institution as a whole, and try to correct deviations if any.

In the field of CSR, the FOS is very important, through which the social performance of the corporation can be accurately evaluated. Each department included in the FOS of the corporation has a mission and a role in this corporation, which must be carried out in accordance with the requirements of CSR. Through evaluating the social performance of the departments (the extent to which the departments adhere to their social responsibilities, economic, legal, ethical and philanthropic), it is possible to know the areas of excellence and failure regarding the commitment of the corporation's departments to their social responsibilities, and thus correction of deviations. The final result "obligation or non-compliance"- which is attributed to the corporation as a whole, is the result of an assessment of the social responsibilities of its departments.

\section{Solving the Problem}

Redefining the Corporate Social Responsibility in Line with the Content of this Study The researcher defines CSR in line with the content of this study as follows: CSR is to achieve the desired economic goals "corporation' $\mathrm{s}$ goals" effectively and efficiently to enhance the corporation's economy and achieve the well-being of the community in which it operates through a package of tasks, duties, activities and initiatives that must be performed by the departments included in the corporation's FOS, in harmony with the applicable laws, codes of ethics and professional code of conduct.

The desired economic goals that must be achieved effectively and efficiently are a clear reference to profit maximization (CER). Maximizing profit - as a desired goal, is achieved only through the effective and efficient performance of the departments included in the corporation's FOS. Effectiveness and efficiency are requirements that must be adhered to by the corporation's departments. From this point of view, it is necessary to define and describe the economic responsibilities of all the corporation's departments, based on the concepts of effectiveness and efficiency in performing the tasks.

\section{Defining the Economic Responsibility of the Departments}

The economic responsibility of the corporation as a whole is profit maximization, which is measured by the profit figure "Be profitable, maximize revenues and minimize expenses." As for the departments included in the corporation's FOS, it means contributing to profit maximization. This contribution can be measured and determined according to the concepts of effectiveness and efficiency in performing the tasks assigned those departments "Be effective and efficient when completing work tasks." 


\subsection{A Precise Description of the Economic Responsibilities of the Departments Included in the Corporation's FOS According to the Concepts of Effectiveness and Efficiency}

Regarding for- profit corporations, the researcher divides the economic responsibilities of departments into two types, general economic responsibility and special economic responsibility.

\section{The General Economic Responsibility of all Departments}

General economic responsibility is the responsibility that all departments included in the corporation's FOS must abide by. It means good use of economic resources allocated to the performance of job duties. General economic responsibility means the following: Preserving fixed assets such as cars and furniture from damage, "good use of fixed assets"; optimum utilization of human resources; as well as economic rationality regarding spending from financial allocations to meet the petty expenses. Non-compliance by the departments with this responsibility leads to higher costs and thus lower profit.

The Special Economic Responsibility of the Departments that Directly Affect the Profit Figure

Special economic responsibility is mainly derived from the nature of the tasks assigned to the department. This type of responsibilities varies from one department to another due to the different nature of the functions assigned to these departments. This type of responsibilities is mainly related to the concepts of effectiveness and efficiency in the performance of tasks. The commitment or non- commitment of the departments to their economic responsibilities contributes to the enhancement or deterioration of the economic performance of the corporation as a whole.

In any industrial corporation, there are four departments that have a direct impact on the economic performance of the corporation as a whole. Those departments are the top management, the purchasing department, the production department, the marketing department. Due to the different functional tasks assigned to these departments, it will be necessary to define and describe the economic responsibilities of these departments as the departments whose tasks have the greatest impact on the profit figure.

In this regard, the economic responsibilities of these departments will be identified and described by describing the functional role of these departments and showing how to perform that role effectively and efficiently. The special economic responsibilities of departments are to accomplish functions effectively and efficiently.

The Corporation's Top Management (TM)

According to NBR ISO 9000:2015 on quality management - Terms and definitions, Top Management "is a person or group of people who directs and controls an 
organization at the highest level." It is also states that "Top management has the power to delegate authority and provide resources within the organization".

This means that top management is who holds authority, resources, decision-making power regarding changes at the company, and leadership (Christino, 2021). Top management is responsible for establishing policies, guidelines and strategic objectives, as well as for providing leadership and direction for departments within the organization. It should also establish those responsible and hold them accountable for a wide variety of management system processes.

\section{The Function of TM}

The functions of TM are many, the most important of which are: 1) Drawing up policies and strategies, and defining the overall goals of the corporation; 2) Directing the process of interaction between the corporation and its surrounding environment; 3) Setting future plans to ensure the achievement of the desired goals; 4) Making decisions and solving problems; 5) Setting Organizational structure of the corporation; 6) Determining the administrative levels and distributing job positions; 7) Searching for the best sources of funding; 8) Distributing economic resources in an optimal way to the departments in the organizational structure; 9) Delegating the authorities and defining responsibilities; 10) Evaluating performance and correcting deviations, etc.

\subsection{Criteria for Evaluating the Efficiency of the TM Performance}

There are a set of criteria for judging the efficiency of the TM in performing its functions. These criteria are:

\section{Harmony among Goals, Plans and Policies}

It is necessary that there be harmony among the objectives, plans, and administrative and financial policies. It is very necessary that the plans developed be compatible with the desired goals. Also, the established policies must be compatible with the plans, in other words, the policies must contribute to achieving the goals. Plans and policies should be on two parallel lines that never contradict each other. Inconsistency among the three components results in undesirable results. Consistency or inconsistency reflects the efficiency or inefficiency of TM in performing its duties.

\section{Feasibility}

Corporation's goals must be realistic and achievable. The plans and policies established to achieve the goals must be implementable and can be adhered to without setbacks. By evaluating the goals, whether they are realistic or imaginary, as well as evaluating the possibility of implementing the plans and the commitment to implement the established policies, it is possible to judge the competence of the TM in the field of setting goals, and designing the plans and policies necessary to achieve those goals. 
Precautionary Measures to Face Threats and Risks

The plans developed to achieve the goals must be characterized by flexibility. In a more precise sense, the plan must be subject to modification when any changes appear in the environment in which the corporation operates. The plan must be adaptable to changes in the environment surrounding the corporation. Rational senior management must always be ready through a package of precautionary measures to address all circumstances and crises that may arise in the future and which are outside the control of the corporation's management. Whenever there are precautionary measures ready to meet complex emerging challenges, the corporation will be safe from economic damage and financial crises.

The external environment in which corporations operate is full of threats and risks that these corporations must always prepare to face through a package of preventive measures to mitigate their impact. Cautious managements in all successful corporations are accustomed to forming reserves and financial provisions to face any force majeure circumstances or unexpected emergencies beyond their control. To judge the efficiency of TM in this regard, all preventive measures that can be adopted to confront the crises created by the external environment- in which the corporation operates, must be evaluated, especially crises that result in the bankruptcy and economic collapse of corporations.

\section{Optimal Distribution of Economic Resources}

To ensure that the economic resources "physical and human" available to the corporation are used in an optimal manner, they must be distributed to all departments- included in the FOS, in a fair manner. The equitable distribution of economic resources contributes to achieving the desired goals of the corporation. Existence of disguised unemployment and financial resources that are in excess of the required limits in some departments refers to the inefficiency of TM in distributing economic resources to departments. Also, the shortage in the volume of labor and financial resources in some departments indicates the inefficiency of TM in distributing economic resources to departments.

\section{Rational Choice}

The distinguished wise leaders of the executive departments can directly contribute to achieving the corporation's goals. Accordingly, the TM must select those leaders according to reasonable criteria such as educational levels, personal skills, etc. Successful and unsuccessful leaders in executive departments can reflect the efficiency and inefficiency of the TM in selecting excellent personalities that can contribute to enhancing the economic performance of the corporation.

\section{Harmony among Policies, Local Laws and International Instruments}

Policies are the corporation's own laws that only everyone who works in it abides by, and that are issued by the corporation's TM. Policies are general directives established by the top management level, taking into account the participation of the following levels "executive departments". Policies are to guide and direct the 
thinking, decisions and actions of managers at the following levels and their assistants to implement the corporation's strategy. The corporation's policies must be compatible with local laws in the country and international instruments issued by international organizations. Inconsistency means the incompetence of the corporation's management in the field of policy development.

\section{Continuous Evaluation and Follow-Up}

In the thought of management and as it is well known that executive departments accomplish their functions "job duties" according to a path specified by the senior management, which should not be ignored or exceeded. That path is specified and described in plans and policies. The Future plans and established policies are mechanisms through which the corporation will be able to achieve its desired goals.

To ensure that the executive departments perform their duties to the fullest, their performance must be continuously monitored and evaluated by the senior management. The most commonly used method of performance appraisal is to compare actual performance with planned performance and correct deviations, if any. The adoption of this method by the senior management can be considered an indication of its competence in this regard.

\subsection{The Economic Responsibility of the TM}

Through its functions, its economic responsibilities of the TM in any profit-seeking corporation is summarized as follows: 1) Translating the corporation's economic goal- which is profit maximization, into executable plans; 2) Determining the appropriate policies to achieve this goal; 3) Providing the necessary economic resources and distributing them to the departments in an optimal way; 4) Determining the functional tasks of all the departments included in the corporation's FOS; 5) Delegating the authorities and defining responsibilities; 6) Evaluating and directing the performance of those departments.

The Meaning of the Concept of Effectiveness in the Functions and Tasks of TM Effectiveness means carrying out all the well-known TM tasks in order to achieve the desired goal of "maximizing profit" such as setting future plans to ensure the achievement of the desired goals, drawing up policies, providing economic resources and distributing them to executive departments, evaluating performance and correcting deviations, etc.

The Meaning of the Concept of Efficiency in the Functions and Tasks of TM Efficiency means the extent to which the TM adheres to the criteria established to measure the quality of performance such as harmony among goals, plans and policies; feasibility; precautionary measures to face threats and risks; optimal distribution of resources; rational choice; harmony among policies, local laws and international instruments; continuous evaluation and follow-up, etc. 


\subsection{Purchasing and Warehouse Department (PWD)}

\section{The Function of PWD}

The function of the PWD in any corporation is to provide the tangible and intangible needs and requirements that the departments included in the FOS of that corporation need in a timely manner and with the required and specified specifications and the lowest possible cost.

\subsubsection{Criteria for Evaluating the Efficiency of the PWD Performance}

Efficiency means providing needs in a way that contributes to strengthening the economy of the corporation. The efficiency of the PWD's performance can be evaluated through three criteria. They are time, quality and cost.

\section{At the Right Timing}

The PWD must provide all the material and non-material needs required by the other departments included in the FOS of the corporation in a timely manner. Providing the needs and requirements at the wrong time "after the specified time and before the specified time" will result in undesirable economic losses. Providing the needs and requirements needed by the requesting departments after and before the specified time has negative repercussions on the results of the economic activity of the corporation as a whole. This failure may lead to a decrease in the volume of revenues or an increase in the volume of costs such as the cost of storage.

\section{With the Required Specifications}

Specifications of needs and requirements must be consistent with the specifications specified by the requesting departments so that these departments can perform their functions effectively and efficiently. In many cases, the violation of the required specifications contributes to causing undesirable damages that affect the economic performance of the corporation as a whole. Failure to comply with the required specifications "the required quality level" may result in wasting materials used in the production of goods or service provision. The procurement of bad needs and requirements by the PWD results in the production of bad goods and services that do not satisfy the customers. This failure affects the reputation of the corporation and thus the loss of customer loyalty in the environment in which it operates.

\section{At the Lowest Cost}

Efficiency also means accomplishing tasks and achieving goals at the lowest possible cost "cost may refer to money, or effort, or quality, or time." The PWD must provide the needs of other departments included in the FOS at the lowest possible cost. Purchasing decisions taken by the PWD must be characterized by economic rationality. In other words, the purchase must be in economic quantities. Those quantities at which inventory costs are at their lowest level. PWD must take into account the following costs when making purchasing decisions: "out of stock cost, the cost of inventory obsolescence, the cost of lost opportunity, the storage 
cost, the costs of orders, benefiting from discounts such as cash discounts and quantity discounts."

\subsubsection{The Economic Responsibility of the PWD}

The economic responsibility of the PWD is to provide all the needs and requirements "such as materials, supplies, equipment, devices, services, etc." needed by the other departments included in the FOS of the corporation, in a timely manner, with the required specifications, and at the lowest possible cost.

The Meaning of the Concept of Effectiveness in the Functions and Tasks of PWD

Effectiveness is the ability of the PWD to provide the needs and requirements of other departments included in the corporation's FOS. In other words, it is the department's ability to accomplish its task, which is to provide the needs and requirements of other departments to help them perform their functions and obligations. Regardless of any criteria that were set to measure the efficiency of the PWD in performing its assigned tasks. Performance effectiveness can be measured by the percentage of tasks completed during a specified period. As for the effectiveness of the PWD in performing its tasks, it can be measured by comparing "the needs and requirements required by the departments with the needs and requirements actually purchased by the PWD during a specific period of time."

The Meaning of the Concept of Efficiency in the Functions and Tasks of PWD Efficiency means the extent to which the PWD adheres to the criteria established to measure the quality of performance such as time, specifications and cost.

\subsection{Production Department (PD)}

\section{The Function of PD}

The function of PM is to manufacture products in the specified quantities according to the set plan, with the required quality specifications, at the specified times, with the same quantities of the specified raw materials "not wasting raw materials," taking into account all requirements necessary to extend the life of manufacturing machines and reduce maintenance costs.

\subsubsection{Criteria for Evaluating the Efficiency of the PD Performance}

Efficiency means producing products in a way that contributes to strengthening the corporation's economy. The efficiency of PD performance can be evaluated through the following five criteria: Production must not be less than and must not exceed the required or planned quantities; the cost of production should not exceed the permissible "planned" limits; Production must be according to the required quality specifications; production at the right times "according to a specific time plan"; it is necessary to take into account all necessary protection measures to protect manufacturing machines to extend their life and reduce maintenance costs. 
PD must be committed to producing the specified "planned" quantities without increasing or decreasing. An increase or decrease in the quantity of units produced may negatively affect the value of expenses or the value of revenues for the corporation as a whole, and then on the profit figure. Production in larger quantities than planned quantities may lead to an increase in storage cost in addition to the possibility of damage to stored products. Production in smaller quantities than planned quantities is a lost opportunity cost. Production in quantities less than the planned quantity may contribute to wasting the opportunity to maximize revenue.

With the same Quantities of the Specified Raw Materials and the same Planned Production Costs

The PD must be committed to implementing everything stated in the estimated budgets with regard to the planned quantities that must be produced and the planned costs necessary to produce those quantities. Violation means the deviation of actual performance from the planned performance. Commitment or non- commitment of the PD to the established plans contributes to the enhancement or deterioration of the economic performance of the corporation as a whole.

In the event that the quantities of raw materials used to produce the planned quantities do not match the quantities of raw materials included in the estimated budget, it means that the quantity of raw materials used in the manufacture of the product is less or more than it should, and this affects the quality of the product and the volume of future revenues, there is a waste of raw materials during the production process that exceeds the permissible limits.

This contributes to the mismatch of the real profit figure with the planned profit figure "contributes to a lower level of planned profit." Actual production costs should not exceed the figures indicated in the estimated budgets (direct materials, direct labor, factory overhead). Exceeding means the low level of efficiency of the $\mathrm{PD}$ in the performance of the functions entrusted to it in comparison with the plans set by the senior management.

\section{With the Required Quality}

The production of goods must be in accordance with the required and specific quality specifications to ensure the continued loyalty of consumers to the goods produced by the corporation. Low level of quality may force them to prefer goods produced by competing corporations. In the competitive market, the commitment or non-commitment of the PD to the required quality specifications directly affects the corporation's reputation and consumer loyalty, and ultimately the corporation's profits. Production of products according to the required quality specifications is one of the most important criteria for measuring the efficiency of the PD in performing its assigned tasks.

\section{At the Right Timing}


Production according to a specific time plan (at the correct times) contributes to reducing the costs of storing produced goods and the risks associated with storing products in warehouses for a long period such as products damage caused by expiration or a decrease in the price of products due to the approaching expiration date. Choosing the appropriate timing for production is one of the criteria for measuring the efficiency of the PD in performing its assigned tasks.

\section{With the Protection of the Manufacturing Machinery}

Attention to cleaning manufacturing machines after each production process, as well as periodic maintenance according to a specific program will contribute to extending the life of these machines and ensure that they do not stop during production operations and reduce maintenance costs to the lowest possible level. Not paying attention to the protection of manufacturing machines "misuse or neglect of periodic maintenance" may contribute to a rise in production costs or a decrease in the volume of revenues and thus a decrease in the value of the corporation's profit. Frequent malfunctions in manufacturing machines and high maintenance costs may reflect the inefficiency of PD in operating and maintaining machines.

\section{The Economic Responsibility of the PD}

The economic responsibility of PD is to produce products in the specified quantities, with the required quality specifications, at the planned costs (materials, labor and other industrial costs), and at the specified times. It should also take into account the need to reduce maintenance costs by adopting the periodic "regular" maintenance system and optimal machines operation in order to extend the life of manufacturing machines.

The Meaning of the Concept of Effectiveness in the Functions and Tasks of PD Effective PD performance means producing the required and specified quantities according to the estimated production budget. Performance effectiveness can be measured by comparing the actual production quantities with the planned production quantities. The effectiveness of the performance of this department is related to its main function, which is production, regardless of any other requirements. Other requirements will reflect the level of performance efficiency.

\section{The Meaning of the Concept of Efficiency in the Functions and Tasks of PD}

Efficiency means the extent to which the PD adheres to the criteria established to measure the quality of performance such as production of the specified quantity, producing the specified quantity using the specified amount of raw materials, production of the specified quantity according to the required quality level, producing the specified quantity at the specified times, production of the specified quantity according to the cost volume specified in the estimated production budget. Also, the efficient performance of this department must include the periodic maintenance of manufacturing machines to avoid economic damages resulting from machine breakdowns. 


\subsection{Marketing Department (MD)}

\section{The Function of $M D$}

The main task of marketing is to know and satisfy the needs and desires of customers. And one of the most important functions that the MD performs "is working to achieve one of the most important objectives of the corporation," which is maximizing profit by selling the quantities produced during the financial period in accordance with the established marketing policies and at the prices specified in the plan "estimated sales budget." MD is the corporation's eye in the market, as it collects the information necessary to accomplish its tasks and achieve its goals, taking into account the study of all strategies adopted by competitors in the market. Also, one of the tasks of the MD is to establish strong relationships with consumers to enhance their loyalty to the produced goods, in addition to opening new marketing channels that did not exist in the past by relying on promotional programs, and providing studies and research on the market for the senior management to help them set the necessary plans and policies.

\subsubsection{Criteria for Evaluating the Efficiency of the MD Performance}

There are a set of criteria for judging the efficiency of the MD in performing its functions. These criteria are:

Selling Products in accordance with the Established Marketing Policies and at the Prices Specified in the Estimated Sales Budget

Selling all or part of the produced units is considered one of the indicators of measuring the effectiveness of the MD in performing its tasks. As for selling the product - regardless of the quantity sold, in accordance with the established marketing policies and at the prices specified in the estimated sales budget, it reflects the efficiency of the MD in performing its tasks and any undesirable deviations from those set policies and prices reflects the inefficiency of this department in performing its duties.

\section{Maintaining the Level of Market Share}

In a competitive market, each corporation has a specific market share "a share of sales that cannot be exceeded due to the presence of competing products produced by other corporations in the market" and it will be necessary to maintain and enhance that market share. This is considered one of the functional obligations of the MD. A decrease in that share in the absence of any circumstances beyond control could reflect the inefficiency of the MD in performing its functions.

Enhancing Consumers' Loyalty to the Produced Goods and Establishing Strong Relationships with them

It is very important for the MD to possess distinct skills on how to deal with consumers to enhance their loyalty to the produced commodity. The resort of some consumers to dealing with competitors in the market means the inefficiency of the MD in performing its tasks unless there are convincing justifications. By tracking 
consumer lists from one financial period to another and identifying changes, the efficiency of MD in this area can be measured.

\section{Opening New Marketing Channels}

Maximizing profit in the competition market by increasing the market share is often a very difficult matter, but it can be achieved by opening new marketing channels in other markets, "regional or international". Increasing the market share, whether at the local, regional or international level, reflects the efficiency of the MD in performing its functions.

\section{Preparing Market Studies and Research on a Logical Basis}

The information that the MD provides to the senior management to prepare the annual plans "estimated budgets" is very important. The failure or success of those plans will depend on the quality of that information. This information can reflect the efficiency or inefficiency of the MD in performing its tasks in the field of studying and evaluating the market situation.

\section{The Economic Responsibility of the MD}

The economic responsibility of the MD is to sell the produced quantities - during the financial period, in accordance with the established marketing policies and at the prices specified in the plan, and to enhance the corporation's position in the market and contribute to maximizing the corporation's profit by opening new marketing channels that did not exist in the past.

\section{The Meaning of the Concept of Effectiveness in the Functions and Tasks of MD}

The main function of the MD or the objective of its presence within the corporation is to sell and market the quantity of products manufactured during a specified period of time. This activity reflects the effectiveness of the MD in performing its assigned task. Effectiveness can be measured by comparing actual sales with planned sales. In addition to the main function, there are other tasks for the MD such as enhancing consumer loyalty. In this regard, the effectiveness can be measured by comparing the list of consumers' names in the past periods with the list of consumers' names in the current period. Opening new marketing channels that did not exist in the past, the effectiveness in this regard can be measured by listing the names of new consumers.

Providing senior management with accurate information required about market conditions through which future plans can be developed to enhance the profit figure. The efficiency of MD in this field can be measured by evaluating the extent to which that information contributes to the success or failure of the plans made by senior management.

The Meaning of the Concept of Efficiency in the Functions and Tasks of MD

The efficiency of the MD can be determined by answering the following question: How did the MD accomplish its functions? Effectiveness is concerned only with the extent of the department's commitment to performing its tasks or achieving its goals, 
while efficiency is concerned with how to perform those tasks. There are a set of criteria for judging the efficiency of the MD in performing its tasks. These criteria are: Selling products in accordance with the established marketing policies and at the prices specified in the estimated sales budget; Maintaining the level of market share; Enhancing consumers' loyalty to the produced goods and establishing strong relationships with them; Opening new marketing channels that did not exist in the past; Preparing market studies and research on a logical basis.

\section{Conclusions}

The appearance of the profit figure in the financial statements means that there is a commitment by the corporation to its economic responsibility, but the quality of that commitment can only be judged by evaluating the economic responsibilities of the departments that contributed to making that figure. Evaluation of the economic responsibilities of the departments can be done by comparing the actual performance with the desired and specified performance according to the criteria of effectiveness and efficiency specified and designed to accomplish the tasks assigned to those departments to the fullest.

To measure the quality of a corporation's commitment to its economic responsibility, the economic responsibilities of the departments that make up the organizational structure of that corporation must be evaluated. In other words, the extent to which departments are committed to performing their duties and functions effectively and efficiently must be evaluated. For each job, there are criteria to judge the extent to which it is performed effectively and efficiently. These criteria may not be clear, but they can be deduced and designed.

By relying on the concepts of effectiveness and efficiency "reasonable criteria to measure the performance of functions efficiently and effectively," this study was able to identify and describe the economic responsibilities of the departments that have the most impact on the profit figure in industrial corporations, namely, the senior management, the purchasing department, the production department and the marketing department.

\section{References:}

Ahmady, Gholam Ali, Mehrpour, Maryam, Nikooravesh, Aghdas. 2016. Organizational Structure. Procedia - Social and Behavioral Sciences, 230, 455-462.

Al Am, AlAline. 2020. The Lebanese Students' Awareness on the Concept of Corporate Social Responsibility. Athens Journal of Business \& Economics, 6(4), 331-348.

Al- Husseini, Amer bin Mohammed. 2017. Accountability and Responsibility. International Economic Al Arab'S Newspaper. https://www.aleqt.com/2017/05/03/article_1181061.html.

Bivins, T.H. 2006. Responsibility and Accountability. doi.org/10.4135/9781452204208.n2.

Carroll, A.B. 1991. The pyramid of corporate social responsibility: Toward the moral management of organizational stakeholders. Business Horizons, 34(4), 39-48. 
Christino, C. 2021. Top management: what is it and what are its responsibilities? https://blog.softexpert.com/en/top-management-and-its-responsibilities/.

Dusenbury, P. 2000. Governing for results: The report of the urban institute's goveming-forresults and accountability project. Washington D.C: The Urban Institute.

Friends of the Earth. 2005. Briefing: Corporate Accountability. http://www.foe.co.uk/resource/briefings/corporate_accountability1.pdf.

Larsen, J.R., Callahan, C. 1990. Performance Monitoring: How It Affects Work Productivity. Journal of Applied Psychology, 75, 530-538.

Nelly, A. 1998. Measuring Business Performance. The Economist Books, P5.

Omosa, R., James, O. 2005. Procurement Performance Measurement Systems: A Survey of Large Manufacturing Companies in Nairobi. A Management Research Project Submitted in Partial Fulfillment of the Requirement for the Degree of Master of Business Administration (MBA), Faculty of Commerce, University of Nairobi.

Saleh, Younis A. Battal. 2021. Corporate Donations as a Source of Financing an Innovative Strategic Economic Plan to Strengthen the National Economy in More Than One Axis in Developing and Poor Countries: A Justified View. Business Innovation \& Entrepreneurship Journal, 3(1), 45-60.

Saleh, Younis A. Battal. 2020. CSR Evaluation: Challenges and contemporary issues. AlHayat Al-Eqtisadiah newspaper, Monday, April 2020

Wilson, M., Wnuk, K., Silvander, J., Gorschek, T. 2018. A Literature Review on the Effectiveness and Efficiency of Business Modeling. e-Informatica Software Engineering Journal, 12(1), 265-302. 